\title{
Quantifying the pain experience in hip and knee osteoarthritis
}

\author{
Rajiv Gandhi MD MS FRCSC, Dmitry Tsvetkov BSc, Herman Dhottar BHSc MD, \\ J Roderick Davey MD FRCSC, Nizar N Mahomed MD ScD FRCSC
}

R Gandhi, D Tsvetkov, H Dhottar, JR Davey, NN Mahomed. Quantifying the pain experience in hip and knee osteoarthritis. Pain Res Manage 2010;15(4):224-228.

PURPOSE: The present study investigated whether the conceptualization of hip and knee osteoarthritis pain implicit in the Western Ontario and McMaster Universities Arthritis Index (WOMAC) and Medical Outcomes Study Short-Form 36 (SF-36) scales is complete, or whether the addition of another scale, such as the Short-Form McGill Pain Questionnaire (MPQ-SF), provides a more complete characterization. Furthermore, the impact that mental health symptoms and catastrophizing had on these scales was investigated.

METHODS: Before hip and knee arthroplasty, 200 patients completed surveys of demographic data, the WOMAC pain scale, the MPQ-SF, the SF-36 Bodily Pain scale, the Pain Catastrophizing Scale and the Hospital Anxiety and Depression Scale. Correlations between scales were calculated and linear regression modelling was used to determine the impact of mental health and catastrophizing on these three pain measures.

RESULTS: A strong correlation between the WOMAC and SF-36 pain scales $(r=-0.70)$ was found; however, both correlated only moderately with the MPQ-SF ( $r=0.36$ and $r=-0.36$, respectively). Linear regression modelling showed that the Pain Catastrophizing Scale significantly predicted a greater score on all three pain scales $(\mathrm{P}<0.05)$.

CONCLUSIONS: The addition of the MPQ-SF appears to add to a more complete quantification of the pain experience in hip and knee osteoarthritis.

Key Words: Arthroplasty; Catastrophizing; Mental health; Osteoarthritis; Pain

Dain is the most common indication for joint replacement surgery (JRS) in an osteoarthritis (OA) population (1). The patient-reported pain experience is affected by physiological (2), psychological (depression and catastrophizing) $(3,4)$ and demographic factors (age, sex and comorbidity) $(5,6)$, which provide great variation in how individuals perceive pain. Accurate measurement of the quality and intensity of the pain may help guide therapeutic strategies and the selection of an appropriate analgesic. Moreover, accurate measurement is important for setting realistic patient expectations because preoperative pain levels have been shown to predict long-term outcomes following JRS (7).

Two of the most commonly used measures of hip and knee OA pain are the Western Ontario and McMaster Universities

\section{Quantification de l'expérience de la douleur dans l'arthrose de la hanche et du genou}

BUT : La présente étude visait à vérifier si la conceptualisation de la douleur arthrosique de la hanche et du genou implicite dans les échelles WOMAC (Western Ontario and McMaster Universities Arthritis Index) et SF 36 (Medical Outcomes Study Short-Form 36) est complète ou si l'ajout d'une autre échelle, comme l'échelle MPQ SF (version abrégée du questionnaire McGill sur la douleur), peut offrir une caractérisation plus complète. En outre, les auteurs ont analysé l'impact des symptômes de santé mentale et du catastrophisme sur ces échelles.

MÉTHODES : Avant une arthroplastie de la hanche et du genou, 200 patients ont répondu à des questionnaires de données démographiques, à l'échelle de mesure de la douleur WOMAC, au MPQ SF, à l'échelle de douleur physique du SF 36, à l'échelle de catastrophisme PCS (Pain Catastrophizing Scale) et à l'échelle HADS (Hospital Anxiety and Depression Scale). Les corrélations entre les échelles ont été calculées et un modèle de régression linéaire a servi à déterminer l'impact de la santé mentale et du catastrophisme sur ces trois mesures de la douleur.

RÉSULTATS : Les auteurs ont trouvé une forte corrélation entre les échelles de la douleur WOMAC et SF $36(r=-0,70)$. Toutefois, les deux n'étaient qu'en corrélation modérée avec le MPQ SF ( $r=0,36$ et $r=-0,36$, respectivement). Le modèle de régression linéaire a montré que l'échelle de catastrophisme était un prédicteur significatif d'un indice plus élevé aux trois échelles de mesure de la douleur $(p<0,05)$.

CONCLUSIONS : Lajout du MPQ SF semble permettre une quantification plus complète de l'expérience de la douleur dans l'arthrose de la hanche et du genou.

Osteoarthritis Index (WOMAC) and the Medical Outcomes Study Short-Form 36 (SF-36) scales; both assess pain with functional activities only. A weakness of having questions in this format is that the pain and function subscales of these measures show significant overlap $(8,9)$. In contrast, scales such as the Short-Form McGill Pain Questionnaire (MPQ-SF) ask about the pain experience in descriptive terms unrelated to functional activities. To date, there are few studies published on the relationship between these various measures in a hip and knee OA population (10). Studies demonstrating a poor correlation between WOMAC and SF-36 scores and patient satisfaction following JRS suggests that the entire pain experience may not be captured by these measures alone, and the addition of another pain scale may be of value $(11,12)$.

Division of Orthopedic Surgery, University of Toronto, Toronto, Ontario

Correspondence: Dr Rajiv Gandhi, Toronto Western Hospital, East Wing 1-439, 399 Bathurst Street, Toronto, Ontario M5T 2 S8.

Telephone 416-603-5642, fax 416-603-3437, e-mail Rajiv.gandhi@uhn.on.ca 
The impact of mental health symptoms on OA patient function has been examined by many authors $(13,14)$; their relationship to OA pain is less well understood. Moreover, most studies focus on knee OA patients; there are few published studies on hip OA patients (15). Three studies $(10,16,17)$ have shown that depression and anxiety correlated with knee OA pain, as measured by the McGill Pain Questionnaire (MPQ); however, these mental health symptoms were no longer significant after adjusting for relevant demographic factors in one study (10). All of these studies used the complete format of the MPQ; one included only female patients, and all samples had fewer than 70 patients. Others (18) have found that symptoms such as fatigue and depression explain some of the variance seen in the WOMAC pain scale for knee OA, but not for hip OA patients. The most commonly used patientreported pain scales by orthopedic surgeons are the WOMAC and SF-36 scales; however, the impact of mental health symptoms on these measures is not well understood (19).

The primary objective of our study was to determine whether the conceptualization of $\mathrm{OA}$ pain implicit in the WOMAC and SF-36 scales is complete, or whether the addition of another scale, such as the MPQ-SF, provides a more complete characterization, inclusive of experiential features. Our secondary objective was to assess the impact of depression, anxiety and pain catastrophizing on patient-reported pain levels for these various measures.

We hypothesized that the MPQ-SF would show little overlap with the WOMAC and SF-36 pain scales, and would be most affected by anxiety, depression and helplessness.

\section{METHODS}

While on a waiting list for hip and knee replacement surgery, patients were recruited to participate in a joint replacement registry in which longitudinal data are collected to record the outcomes of surgery. From the registry, data on 100 consecutive hip replacement patients and 100 consecutive knee replacement patients undergoing JRS for a diagnosis of OA were extracted during 2007. Patients were excluded if they had a diagnosis of inflammatory arthritis or post-traumatic OA. All patients provided consent to participate through an independent study coordinator not involved in the medical care of the patients. The study protocol was approved by the local human subjects review board.

Demographic data including age, sex and body mass index (BMI) were collected by patient self-report. BMI was defined as body weight in kilograms divided by the square of height in metres $\left(\mathrm{kg} / \mathrm{m}^{2}\right)$. Comorbidity data were collected from the 14 categories of chronic illness from the Cumulative Illness Rating Scale $(20,21)$. This scale encompasses the domains of cardiac; vascular; hematological; respiratory; otorhinolaryngological and ophthalmological; upper gastrointestinal; lower gastrointestinal; hepatic and pancreatic; renal; genitourinary; musculoskeletal and tegumental; neurological; endocrine, metabolic and breast; and psychiatric systems.

\section{Outcomes assessment}

At a maximum of three weeks before surgery, all patients completed the validated scales.

The WOMAC pain scale consists of five questions that assess pain while walking on a flat surface, going up or down stairs, in bed at night, sitting or lying, and standing upright. Responses are recorded on a five-point Likert scale, with a higher score representing a greater level of pain. This scale has been shown to be valid and reliable in hip and knee OA populations (22). The WOMAC directs the patient to answer the questions as they relate to the hip or knee of interest.

The SF-36 encompasses eight domains of health-related quality of life and has been widely used in OA populations (23). The Bodily Pain (BP) domain was focused on, which is a two-item scale that asks about overall pain intensity and how much the pain interfered with activities over the previous four weeks. Responses are recorded on a five-point Likert scale and then transformed onto a 100-point scale on which a higher score represents a better health state and less pain. A potential limitation of this scale is that the two pain questions do not relate to a single anatomical site, but rather ask about bodily pain in general and may have limited application for jointspecific diseases.

The MPQ-SF consists of 15 descriptive terms that fall into the categories of sensory (eg, sharp and stabbing), affective (eg, punishing-cruel) and evaluative aspects of the pain experience (eg, tiring-exhausting) (24). The patient subjectively rates each term on a four-point Likert scale ranging from none to severe. Patients then rate their pain on a visual analogue scale and also rate the overall intensity of the pain on a five-point scale ranging from no pain to excruciating pain (24). A higher score on the MPQ-SF represents more pain.

Pain catastrophizing is an inflated, negative emotional state that arises from pain (25). Catastrophizing behaviour leads patients to develop expectancies for the threat of a painful stimulus; the cognitive interpretation of these signals may lead to a greater perception of pain $(25,26)$. On the Pain Catastrophizing Scale (PCS), patients rate how often they experience the 13 scenarios related to pain catastrophizing behaviour on a four-point scale with responses ranging from 'not at all' to 'all the time'. Examples of the scenarios include 'I worry all the time about whether the pain will end' and 'I feel I can't go on'. The PCS adds to a total score and has three subscales - magnification, helplessness and rumination. The present study focused on the total score (27). The PCS has been shown by others (28) to be a significant predictor of perioperative pain with knee replacement surgery, and also to predict ongoing patient-reported pain two years after surgery $(4,29)$.

The Hospital Anxiety and Depression Scale (HADS) is a 14-item measure that was validated for use as a screening tool, rather than a quantification tool, for anxiety and depression $(30,31)$. Each item has four response choices ranging from none to severe. A summary score is then obtained from the seven items in each of the anxiety (HADS-A) and depression (HADS-D) subscales. This scale was chosen because many authors (32) have shown that there is an overlapping relationship between the symptoms of OA, such as difficulty sleeping, low energy levels and signs of depression. Moreover, focus groups (9) evaluating the pain experience in hip and knee OA demonstrated quite clearly that the pain negatively affects a patient's mood and elevates anxiety levels.

\section{Statistical analysis}

Continuous data such as age, BMI and outcome scores were compared between groups using $t$ tests because the data were 


\begin{tabular}{|c|c|c|c|c|c|c|}
\hline & 1 & 2 & 3 & 4 & 5 & 6 \\
\hline \multicolumn{7}{|l|}{ 1. SF-36 BP } \\
\hline 2. WOMAC & $-0.70^{\star}$ & & & & & \\
\hline 3. HADS-A & $-0.27^{*}$ & $0.29^{*}$ & & & & \\
\hline 4. HADS-D & $-0.40^{\star}$ & $0.35^{*}$ & $0.52^{\star}$ & & & \\
\hline 5. MPQ-SF & $-0.36^{\star}$ & $0.36^{*}$ & $0.41^{*}$ & $0.43^{\star}$ & & \\
\hline 6. PCS & $-0.40^{*}$ & $0.48^{*}$ & $0.61^{*}$ & $0.61^{*}$ & $0.61^{*}$ & \\
\hline
\end{tabular}

${ }^{*} P<0.01$. MPQ-SF Short-Form McGill Pain Questionnaire; SF-36 BP Medical Outcomes Study Short-Form 36 Bodily Pain scale; WOMAC Western Ontario and McMaster Universities Osteoarthritis Index pain scale

normally distributed. Means and SDs were reported for all continuous variables. Categorical data such as sex were reported with frequencies, and groups were compared using the Fisher's exact test.

The relationships between the pain scores, PCS and HADS were assessed using the Spearman's correlation coefficient because not all data were normally distributed. The correlation was defined as weak if the coefficient was less than 0.3, moderate if it was between 0.3 and 0.5 , and strong if it was greater than 0.5 (33). Considering that the correlation matrix (Table 1) represents 10 statistical comparisons, the alpha level was corrected to 0.01 . The correlations for the hip and knee patients were initially calculated separately, but a similar pattern was found and, therefore, the combined data were presented.

Three separate linear regression models were built to examine the relationship between the constructs of catastrophizing, anxiety and depression, and the three pain scales. The predictors of interest were the PCS, HADS-A and HADS-D, while the dependent variables were the SF-36 BP scale, the WOMAC pain scale and the MPQ-SF. All models were adjusted for age, sex, BMI, procedure (hip versus knee) and medical comorbidity. Any collinearity between the predictors was assessed for in the regression models using tolerance statistics. All variables were retained in the models regardless of whether they reached statistical significance to maintain face validity of the models.

All statistical analysis was performed with SPSS version 13.0 (SPSS Inc, USA). All P values were two tailed, with an alpha of 0.05 unless otherwise specified.

\section{RESULTS}

In the cohort of 200 patients, the mean age was 65.9 years, $42 \%$ were men and the mean BMI was $29.4 \mathrm{~kg} / \mathrm{m}^{2}$. There were no differences in pain, anxiety or depression scores between hip and knee patients. All demographic and outcomes data for the hip and knee patients are presented in Table 2.

The Spearman's correlation coefficients demonstrated a strong association between the WOMAC and SF-36 BP scores $(r[98]=-0.70, P<0.01)$. The correlations between the WOMAC and MPQ-SF scores, and the SF-36 BP and MPQ-SF scores, were $r(98)=0.36$ and $r(98)=-0.36$, respectively. Moderatestrong correlations were seen between the MPQ-SF, and the PCS, HADS-A and HADS-D scores ( $r[98]=0.41$ to 0.61 , $\mathrm{P}<0.01$ ). All correlation coefficients are presented in Table 1 .

Linear regression modelling demonstrated that greater pain catastrophizing was a significant predictor of a greater pain
TABLE 2

Demographic and outcomes data compared across hip and knee osteoarthritis patients

\begin{tabular}{lccc}
\hline & \multicolumn{2}{c}{ Osteoarthritis patients } & \\
\cline { 2 - 3 } & Hip $(\mathbf{n}=\mathbf{1 0 0})$ & Knee $(\mathbf{n}=\mathbf{1 0 0})$ & $\mathbf{P}$ \\
\hline Age, years & $62.7 \pm 10.6$ & $66.5 \pm 8.4$ & 0.07 \\
Men, \% & 50 & 31 & 0.06 \\
Body mass index, $\mathrm{kg} / \mathrm{m}^{2}$ & $28.4 \pm 5.2$ & $29.3 \pm 4.2$ & 0.41 \\
Comorbidity, $\mathrm{n}$ & $2.5 \pm 1.4$ & $2.9 \pm 1.5$ & 0.13 \\
WOMAC pain score & $9.4 \pm 4.6$ & $9.9 \pm 3.6$ & 0.54 \\
MPQ-SF score & $17.5 \pm 10.1$ & $19.5 \pm 10.2$ & 0.37 \\
SF-36 BP score & $38.2 \pm 18.3$ & $36.9 \pm 17.6$ & 0.75 \\
Pain Catastrophizing Scale score & $16.6 \pm 13.7$ & $17.3 \pm 13.3$ & 0.80 \\
HADS anxiety subscale score & $6.3 \pm 4.0$ & $6.4 \pm 3.9$ & 0.79 \\
HADS depression subscale score & $5.5 \pm 3.6$ & $4.9 \pm 3.1$ & 0.32 \\
\hline
\end{tabular}

Data presented as mean $\pm S D$ unless otherwise indicated. HADS Hospital Anxiety and Depression Scale; MPQ-SF Short-Form McGill Pain Questionnaire; SF-36 BP Medical Outcomes Study Short-Form 36 Bodily Pain scale; WOMAC Western Ontario and McMaster Universities Osteoarthritis Index

score on all scales $(\mathrm{P}<0.05$; Table 3$)$. The HADS-A and HADS-D scores did not reach statistical significance in predicting the pain scores for any of the three scales. There was no substantial collinearity found between the predictors.

\section{DISCUSSION}

Pain is a subjective experience and attempts to quantify it are affected by each individual's unique perception of what pain is. The findings of our study indicate that there is a strong correlation among pain scores that are based on functional questions (WOMAC pain scale and SF-36 BP scale); however, scores from these two scales correlate only moderately with the scores obtained from the MPQ-SF, which quantifies pain severity based on descriptive adjectives. We found that none of the pain scales evaluated in the present study were significantly affected by anxiety and depression levels, while greater levels of catastrophizing were associated with greater pain on all three pain scales.

There are few published studies examining the relationships between pain scales in hip and knee OA. One group (10) studied 68 knee OA patients and found a correlation of -0.38 between the WOMAC pain scale and the full-length MPQ, while we reported a similar correlation of -0.36 . Studies $(8,34)$ evaluating the construct validity of the WOMAC pain scale have shown a strong correlation with the SF-36 BP scale $(\mathrm{r}=-0.6)$, and is similar to the correlation of -0.70 found in our study. Our study adds new information by examining both hip and knee $\mathrm{OA}$ patients, and also by examining the relationship between the MPQ-SF and the SF-36 BP scale.

The importance of mental health symptoms such as depression and anxiety in predicting pain as measured by the MPQ has been shown in a few studies $(10,16,17)$. In addition, one study (18) demonstrated an association between depressive symptoms and greater pain on the WOMAC scale for hip and knee OA patients, while another (10) showed no association in a knee OA population. We did not find any published studies examining the impact of mental health symptoms on the SF-36 BP scale in OA. In our data set, anxiety and depression were not significant predictors of a greater pain score for hip and knee OA patients on any of the three pain scales.

Catastrophizing is a negative emotional state anticipating a painful experience (25). Roth et al (28) examined the 
TABLE 3

Linear regression modelling predicting pain scores before surgery for hip and knee osteoarthritis patients

\begin{tabular}{|c|c|c|c|c|c|c|c|c|c|}
\hline & \multicolumn{3}{|c|}{ SF-36 BP } & \multicolumn{3}{|c|}{ WOMAC } & \multicolumn{3}{|c|}{ MPQ-SF } \\
\hline & B & SE B & $\beta$ & B & SE B & $\beta$ & B & SE B & $\beta$ \\
\hline Age & 0.1 & 0.2 & 0.06 & -0.07 & 0.03 & $-0.2^{\star}$ & -0.1 & 0.06 & $-0.1^{*}$ \\
\hline Sex & -2.7 & 3.1 & -0.07 & 1.2 & 0.6 & 0.1 & 1.3 & 1.3 & 0.07 \\
\hline Comorbidity & -0.7 & 0.9 & -0.06 & 0.3 & 0.2 & 0.13 & 0.9 & 0.4 & $0.2^{*}$ \\
\hline Proc & -5.1 & 3.2 & -0.1 & 0.2 & 0.7 & 0.02 & -1.9 & 1.4 & -0.1 \\
\hline PCS & -0.4 & 0.1 & $-0.3^{*}$ & 0.1 & 0.03 & $0.4^{\star \star}$ & 0.4 & 0.06 & $0.5^{\star \star}$ \\
\hline HADS-D & -1.0 & 0.6 & -0.2 & 0.1 & 0.1 & 0.1 & 0.4 & 0.2 & 0.1 \\
\hline Model $\mathrm{R}^{2}$ & & 0.26 & & & 0.33 & & & 0.46 & \\
\hline$F$ value & & $5.1^{\star \star}$ & & & $6.8^{\star \star}$ & & & $15.5^{\star \star}$ & \\
\hline
\end{tabular}

No evidence of collinearity was found between predictors. ${ }^{*} P<0.05 ;{ }^{* *} P<0.01$. $\beta$ Standardized beta coefficients; $B$ Unstandardized beta coefficients; BMI Body mass index; HADS-A Hospital Anxiety and Depression Scale anxiety subscale; HADS-D Hospital Anxiety and Depression Scale depression subscale; MPQ-SF Short-Form McGill Pain Questionnaire; PCS Pain Catastrophizing Scale; Proc Procedure (hip versus knee); SE Standard error; SF-36 BP Medical Outcomes Study ShortForm 36 Bodily Pain scale; WOMAC Western Ontario and McMaster Universities Osteoarthritis Index pain scale

relationship between catastrophizing and knee OA pain as measured by the MPQ before surgery, but demonstrated a poor correlation of 0.33 , while we found a strong correlation of 0.61 . Other authors $(35,36)$ have also shown that catastrophizing correlates with greater pain severity in knee OA patients. We found through regression modelling that greater levels of catastrophizing were associated with greater pain on all three pain scales.

The first limitation of our study is that although our regression models have face validity with the covariates entered, factors such as social supports at home and ethnicity should be explored in future studies. Second, we studied a patient population from a single academic hospital and future work should

\section{REFERENCES}

1. Dieppe P, Basler HD, Croft CP, et al. Knee replacement surgery for osteoarthritis: Effectiveness, practice variations, indications and possible determinants of utilization. Rheumatology 1999;38:73-83.

2. Melzack R, Casey KL. Sensory, motivational, and central control determinants of pain: A new conceptual model. In: Kenshalo D, ed. The Skin Senses. Springfield, Illinois: Thomas, 1968:423-43.

3. Lingard EA, Riddle DL. Impact of psychological distress on pain and function following knee arthroplasty. J Bone Joint Surg Am 2007;89:1161-9.

4. Forsythe ME, Dunbar M, Hennigar AW, Sullivan MJL, Gross M. Prospective relation between catastrophizing and residual pain following knee arthroplasty: Two-year follow up. Pain Res Manage 2008;13:335-41.

5. Bourne RB, McCalden RW, MacDonald SJ, Mokete L, Guerin J. Influence of patient factors on TKA outcomes at 5 to 11 years follow-up. Clin Orthop Rel Res 2007;464:27-31.

6. Katz JN, Wright EA, Guadagnoli E, Liang MH, Karlson EW, Cleary P. Differences between men and women undergoing major orthopedic surgery for degenerative arthritis. Arthritis Rheum 1994:37:687-94.

7. Brander V, Gondek S, Martin E, Stulberg SD. Pain and depression influence outcome 5 years after knee replacement surgery. Clin Orthop Rel Res 2007;464:21-6.

8. Salaffi F, Leardini G, Canesi B, et al. Reliability and validity of the Western Ontario and McMaster Universities (WOMAC) Osteoarthritis Index in Italian patients with osteoarthritis of the knee. Osteoarthritis Cartilage 2003;11:551-60.

9. Hawker GA, Stewart L, French MR, et al. Understanding the pain experience in hip and knee osteoarthritis - an OARSI/OMERACT initiative. Osteoarthritis Cartilage 2008;16:3415-22.

10. Creamer P, Lethbridge-Cejku M, Hockberg MC. Determinants of pain severity in knee osteoarthritis: Effect of demographic and be directed toward a multicentre study to improve the generalizability of our findings.

\section{CONCLUSION}

The WOMAC pain and SF-36 BP scales appear to measure different aspects of pain than the MPQ-SF in a hip and knee OA population. Our study adds to the literature by providing data on hip OA patients because they have not been well studied in the past. We believe that patients should be assessed with the MPQ-SF and either the WOMAC pain scale or the SF-36 BP scale before JRS to best quantify the complete pain experience. Accurate quantification of pain levels will help guide therapeutic strategies and more accurately risk-stratify patients to better predict outcomes of JRS.

psychosocial variables using 3 pain measures. J Rheumatol 1999;26:1785-92.

11. Noble PC, Conditt MA, Cook KF, Mathis KB. The John Insall Award: Patient expectations affect satisfaction with total knee arthroplasty. Clin Orthop Relat Res 2006;452:35-43.

12. Gandhi R, Davey JR, Mahomed NN. Predicting patient dissatisfaction following joint replacement surgery. J Rheumatol 2008;35:2415-8.

13. Maly MR, Costigan PA, Olney SJ. Determinants of self-report outcome measures in people with knee osteoarthritis. Arch Phys Med Rehabil 2006;87:96-104.

14. Creamer P, Lethbridge-Cejku M, Hochberg MC. Factors associated with functional impairment in symptomatic knee osteoarthritis. Rheumatol 2000;39:490-6.

15. Creamer P, Lethbridge-Cejku M, Costa P, Tobin JD, Herbst JH, Hochberg MC. The relationship of anxiety and depression with self-reported knee pain in the community: Data from the Baltimore Longitudinal Study of Aging. Arthritis Care Res 1999;12:3-7.

16. Summers MN, Haley WE, Reveille JO, Alarcon GS. Radiographic assessment and psychological variables as predictors of pain and functional impairment in osteoarthritis of the knee or hip. Arthritis Rheum 1988;31:204-9.

17. Salaffi F, Cavalieri F, Nolli M, Ferraccioloi G. Analysis of disability in knee osteoarthritis. Relationship with age and psychological variables but not with radiographic score. J Rheumatol 1991;18:1581-6.

18. Wolfe F. Determinants of WOMAC function, pain and stiffness scores: Evidence for the role of low back pain, symptom counts, fatigue and depression in osteoarthritis, rheumatoid arthritis and fibromyalgia. Rheumatology 1999;38:355-61.

19. Ethgen O, Bruyere O, Richy F, Dardennes C, Reginster JY. Health related quality of life in total hip and total knee 
arthroplasty: A qualitative and systematic review of the literature. J Bone Joint Surg 2004;86:963-74.

20. Linn BS, Linn MW, Gurel L. Cumulative illness rating scale. J Am Geriatr Soc 1968;16:622-6.

21. Miller MD, Paradis CF, Houck PR, et al. Rating chronic medical illness burden in geropsychiatric practice and research: Application of the Cumulative Illness Rating Scale. Psychiatry Res 1992;41:237-48.

22. Bellamy N, Buchanan WW, Goldsmith CH, et al. Validation study of WOMAC: A health status instrument for measuring clinically important patient relevant outcomes following total hip or knee arthroplasty in osteoarthritis. J Rheumatol 1988;15:1833-40.

23. Kosinski M, Keller SD, Hatoum HT, Kong SX, Ware JE Jr. The SF-36 Health Survey as a generic outcome measure in clinical trials of patients with osteoarthritis and rheumatoid arthritis: Tests of data quality, scaling assumptions and score reliability. Med Care 1999;37(5 Suppl):MS10-22.

24. Melzack R. The Short-Form McGill Pain Questionnaire. Pain 1987;30:191-7.

25. Sullivan MJL, Thorn B, Jennifer AH, et al. Theoretical perspectives on the relation between catastrophizing and pain. Clin J Pain 2001; 17:52-64.

26. Turk DC, Rudy TE. Cognitive factors and persistent pain: A glimpse into Pandora's box. Cog Ther Res 1992;16:99-122.

27. Sullivan MJ, Bishop SR, Pivik J. The pain catastrophizing scale: Development and validation. Psychol Assess 1995;7:524-32.

28. Roth ML, Tripp DA, Harrison MH, Sullivan M, Carson P. Demographic and psychosocial predictors of acute perioperative pain for total knee arthroplasty. Pain Res Manage 2007;12:185-94.

29. Edwards RR, Haythornthwaite JA, Smith MT, Klick B, Katz JN. Catastrophizing and depressive symptoms as prospective predictors of outcomes following total knee replacement. Pain Res Manage 2009;14:307-11.

30. Herrmann C. International experiences with the hospital anxiety and depression scale - a review of validation data and clinical results. J Psychosom Res 1997;42:17-41.

31. Zigmund AS, Snaith RP. The hospital anxiety and depression scale. Acta Psychiatr Scand 1983;67:361-70.

32. Brandt KD, Heilman DK, Slemenda C, et al. A comparison of lower extremity muscle strength, obesity, and depression scores in elderly subjects with knee pain with and without radiographic evidence of knee osteoarthritis. J Rheumatol 2000;27:1937-46.

33. Cohen J. Statistical Power Analysis for the Behavioral Sciences, 2nd edn. Hillsdale: Lawrence Erlbaum, 1988.

34. Escobar A, Quintana JM, Bilbo A, Azkarate J, Guenaga JI. Validation of the Spanish version of the WOMAC questionnaire for patients with hip or knee osteoarthritis. Clin Rheumatol 2002;21:1434-49.

35. Keefe FJ, Lefebvre JC, Egert JR, Affleck G, Sullivan MJ, Caldwell DS. The relationship of gender to pain, pain behavior, and disability in osteoarthritis patients: The role of catastrophizing. Pain 2000;87:325-34.

36. Keefe FJ, Affleck G, France CR, et al. Gender differences in pain, coping, and mood in individuals having osteoarthritic knee pain: A within-day analysis. Pain 2004;110:571-7. 


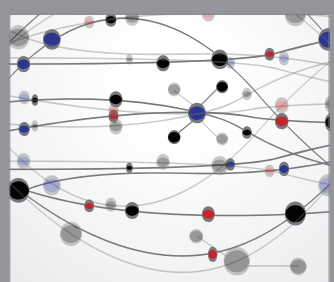

The Scientific World Journal
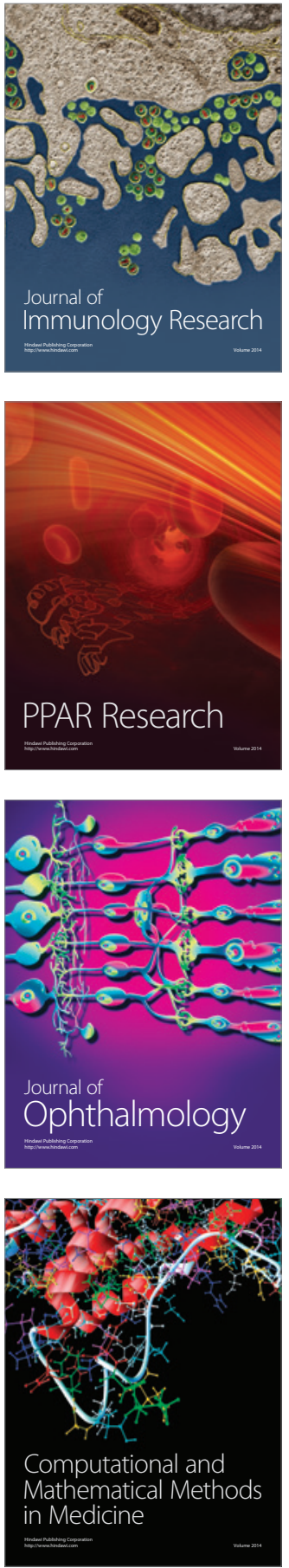

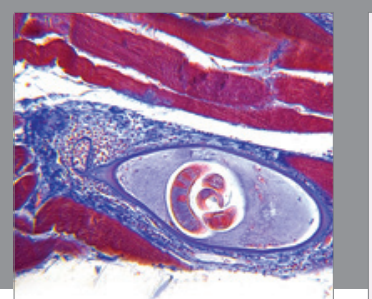

Gastroenterology Research and Practice

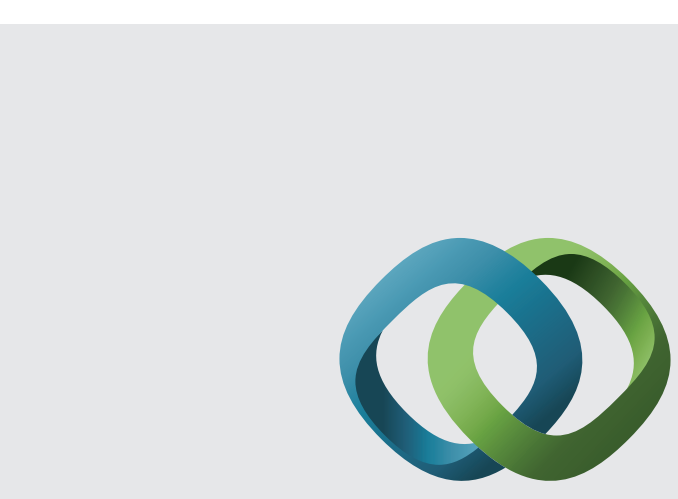

\section{Hindawi}

Submit your manuscripts at

http://www.hindawi.com
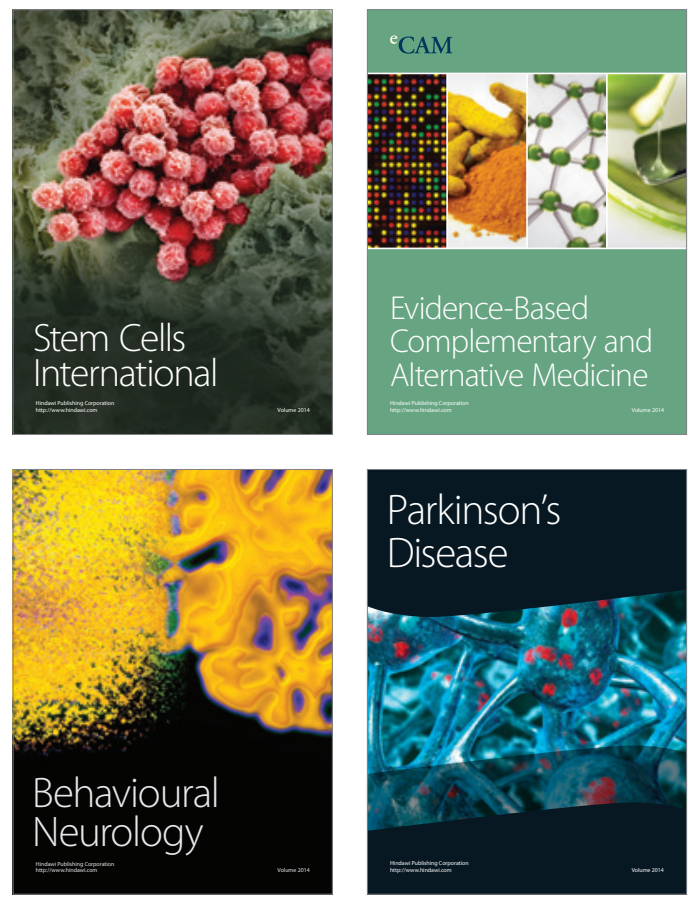
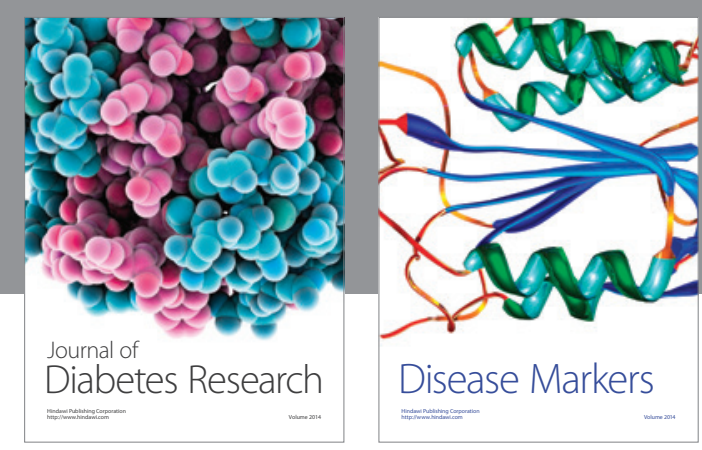

Disease Markers
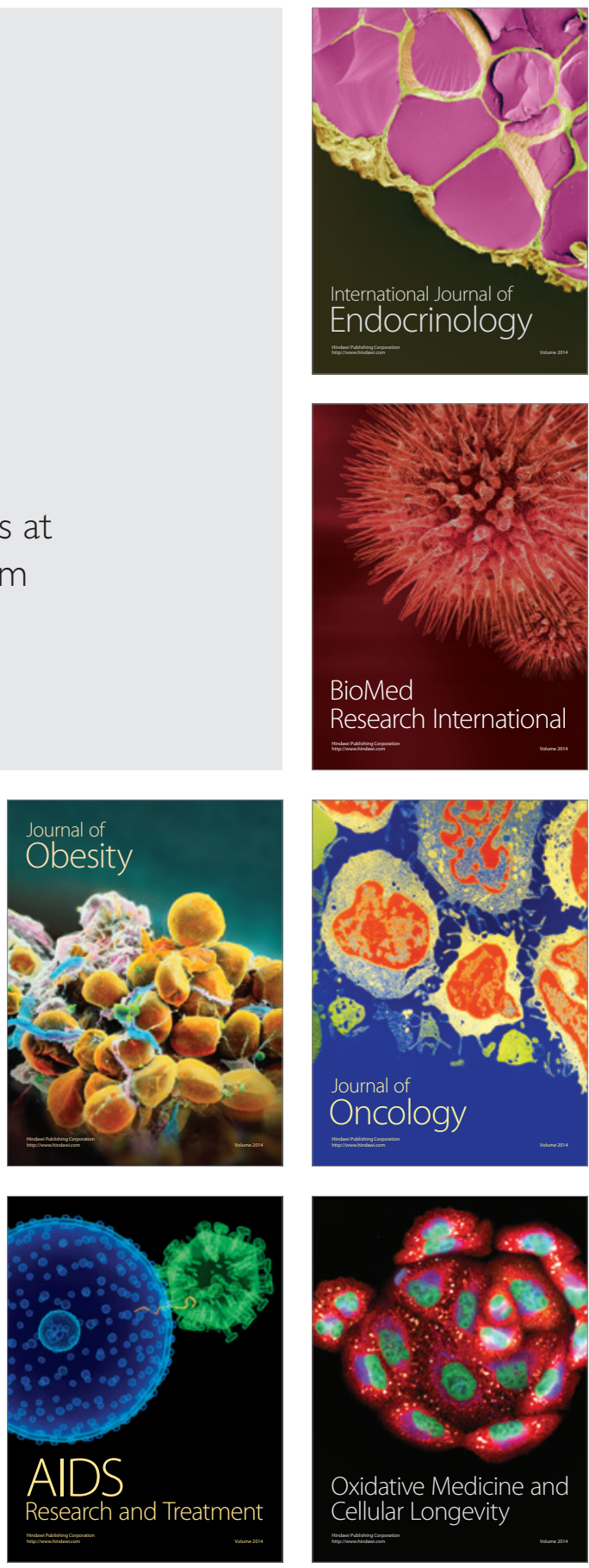